\title{
Review
}

\section{Lacrimal Stents and Intubation Systems - our expertise}

\author{
ALINA POPA CHERECHEANU ${ }^{1,2}$, MIHAI GHITA ${ }^{1,2}$, IRINA GHEORGHE ${ }^{3,4}$, VLAD BUDU ${ }^{1,5}$ \\ 1"Carol Davila" University of Medicine and Pharmacy, B-dul Eroilor Sanitari 8, 050474 Bucharest, Romania \\ ${ }^{2}$ Dept. of Ophtalmology, Universitary Hospital Bucharest, Splaiul Independentei 169, 050098, Bucharest, \\ Romania \\ ${ }^{3}$ Department of Microbiology and Immunology, Faculty of Biology, University of Bucharest, Romania \\ ${ }^{4}$ Research Institute of the University of Bucharest (ICUB), Bucharest, Romania \\ ${ }^{5}$ Institute of Phonoaudiology and Functional ENT Surgery "Prof. Dr. D. Hociotă”, Bucharest, Romania
}

\begin{abstract}
In the last years a series of materials and surgical techniques have been developed for patient with lacrimal drainage obstruction in trying to solve the pathology associated with minimal invasion and a fast recovery. The traditional surgeries, frequently, are very laborious which in many situations require general anesthesia and a long recover. We aimed to present the possibilities of recovering the obstructed lacrimal pathway from the ophtalmologic point of view (lacrimal puncta plugs, monocanalicular intubation, bicanalicular stents, nasolacrimal duct catheterization) and also from the expertise of the ENT practitioner (endoscopic dacriocystorhinostomy and double margin stent technique). Based also on the literature available data it has been concluded that there are medical treatments for all of the lacrimal obstructive pathologies and depending the etiology of the lacrimal pathology it can be decide the optimal solutions.
\end{abstract}

Keywords Lacrimal pathway, lacrimal stent, endoscopic dacryocystorhinostomy.

To cite this article: CHERECHEANU AP, GHITA M, GHEORGHE I, BUDU V. Lacrimal Stents and Intubation Systems - our expertise. Rom Biotechnol Lett. 2020; 25(3): 1651-1657. DOI: $10.25083 / \mathrm{rbl} / 25.3 / 1651.1657$

*Corresponding author: MIHAI GHITA, "Carol Davila" University of Medicine and Pharmacy, B-dul Eroilor Sanitari 8, 050474, Bucharest, Romania

E-mail: ghita.amg@gmail.com 


\section{Introduction}

Lacrimal production is a continuous process and the tears are evacuated through the lacrimal pathways towards the inferior nasal meatus by capillarity, suction and gravity. A defective drainage due to stenosis/obstruction along the lacrimal drainage system, to malposition of the lacrimal puncta and/or to a lacrimal pump failure, in the absence of hypersecretion secondary to an ocular disease, results in an overflow of tears onto the face, known as epiphora (NEMET [1]).

The lacrimal pathway consists of superior and inferior lacrimal puncta and canaliculi, common canaliculus, lacrimal sac and the nasolacrimal duct (ORGE \& BOENTE [2]).

The lacrimal punctum sits medially to the most inner Meibomian gland opening and it is circumscribed by a dense sclerous fibrous tissue which allows a clear passage through the puncta. The diameter ranges from 0.2 to $0.5 \mathrm{~mm}$. The superior and inferior lacrimal canaliculi pass vertically in the tarsal plate from the lacrimal puncta for about $2 \mathrm{~mm}$ before changing direction horizontally for another $7-15 \mathrm{~mm}$. At that point, the canaliculus has a slightly dilated portion called the ampullae which contrary to the old believes it is not involved in the suction of tears (ORGE \& BOENTE [2]; WURDEMANN [3]).

Because of its elasticity, the horizontal pathway can dilate up to three times its diameter during probing; its dimensions are controlled by Horner's muscle, part of the orbicularis oculi muscle. Muscle fibers that run anterior and posterior to the lacrimal canaliculus compress and dilate it with each blink ( AHL \& HILL [4]; KAKIZAKI [5]).

Often the superior and inferior canaliculi join into a common canaliculus which opens on the lateral wall of the lacrimal sac which lies vertically along the nasal wing, in the lacrimal fossa. It consists of a superior portion called "cul-de-sac", a middle portion under the medial canthal tendon and an inferior portion behind the lacrimal crease which continues with the nasolacrimal duct (ORGE \& BOENTE [2]; KAKIZAKI, [5]; FAYET et al [6]).

Prior to do any surgical technique for the lacrimal drainage system, it is necessary to make sure there is an epiphora (watery eyes) and where it is the obstruction. In order to diagnose the epiphora a series of tests can be performed. The simplest ways is the primary and secondary Jones tests. Primary Jones test assume the instillation of fluoresceine into the conjunctival sac and following after 5 minutes the fluoresceine into the nose with the cotton tipped bud moistened in topical anesthetic. The test shows the permeability of the lacrimal path but in case of obstruction also can identify stenosis place. Prior to irrigate or probing the lacrimal path it is required to dilate the inferior lacrimal punctum (Figure 1). The second test is based on the nasolacrimal duct probing and irrigation with a blunt lacrimal canula using sodium chloride solution through the lacrimal punctum (Fig. 2).

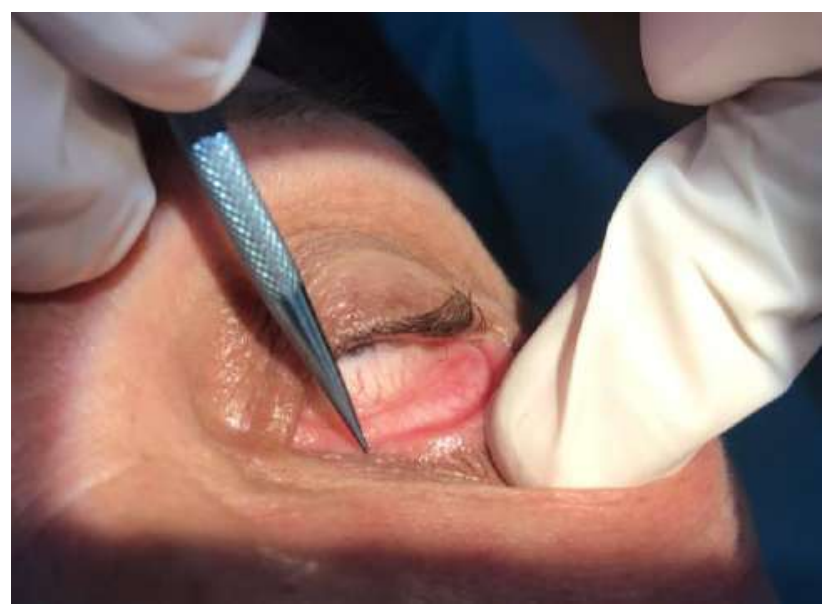

Figure 1. The aspect of the dilatation of lacrimal punctum.

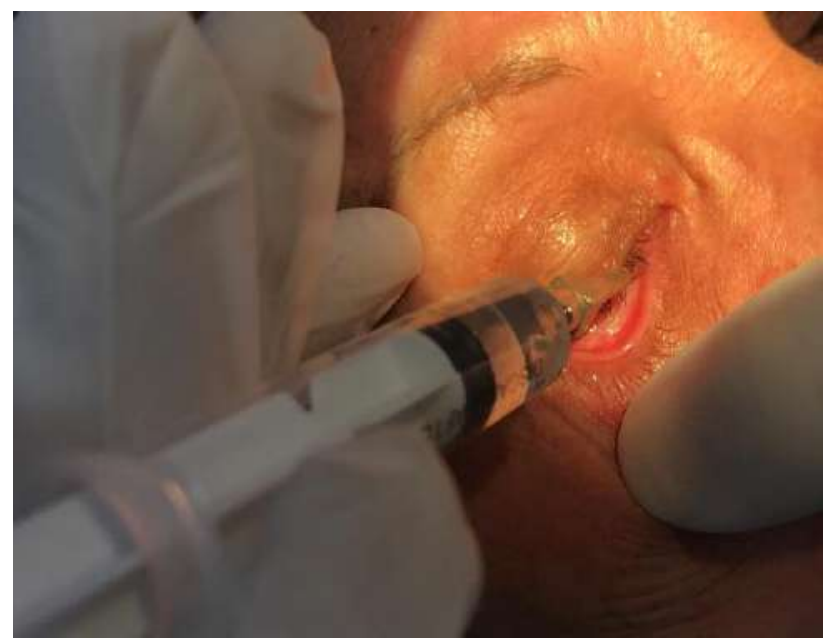

Figure 2. The nasolacrimal duct probing and the irrigation.

If the test is negative it is necessary to introduce a Bowmann probe (Fig. 3) through the lacrimal canaliculum, the common canaliculum, the lacrimal sac and eventually the naso-lacrimal duct. It is preferable to use a thicker Bowman probe, 2 or 3 instead of a thin one $(1,0$ or 00$)$ because the thin Bowmann probe can make a false path which can lead to hemorrhage and fibrosis. Depending on the place and the degree of obstruction, it is possible to choose between different intubation stents and techniques.

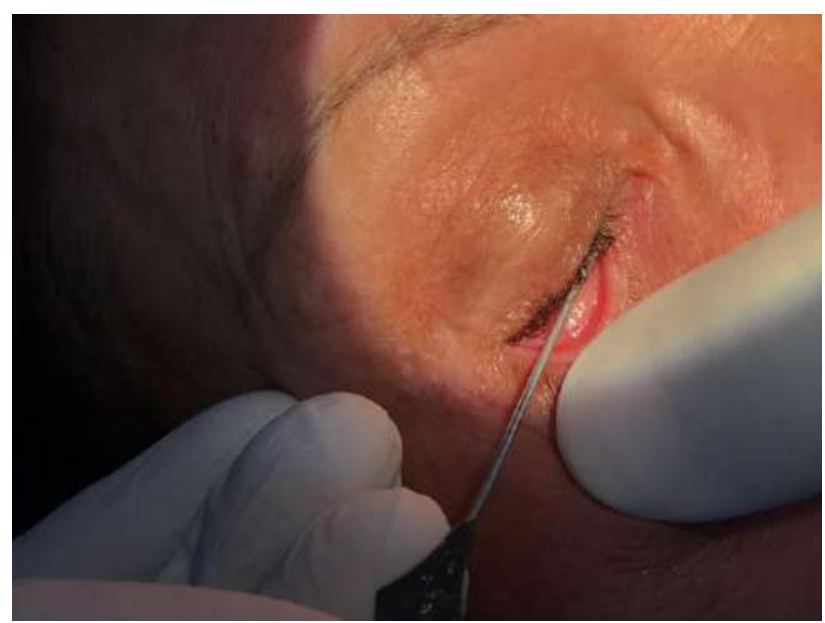

Figure 3. The insertion of Bowmann probe. 


\section{Punctal plugs occlusion}

A stable tear film needs a good balance between tear production and tear drainage. In moderate to severe disease, punctal occlusion can be performed, in order to reduce the loss of tears through the drainage system (ERVIN et al [7]). We can occlude temporary or reversible the inferior and/or the superior punctum depending on the presence or absence of epiphora, using different plugs.

Silicone plugs are prepackaged with disposable devices ensuring the achievement a good insertion into the desired punctum. Plugs are available in different sizes, depending on the size of the lacrimal puncta, with a diameter ranging from 0.45-1 mm and a length between 1.35-2 mm (ERVIN et al [7]).

More easy and convenient for surgeons could be the smart Plugs.

The smart plugsconsist of a biocompatible acrylate with physical and chemical properties related to the temperature and degree of hydration of the environment. The plugs are available with a diameter of $0.4 \mathrm{~mm}$ and a length of $6 \mathrm{~mm}$. After introducing into the lacrimal puncta, at body temperature and in saline solution their dimensions will be reduced e.g. $1 \mathrm{~mm}$ in diameter and $1.5 \mathrm{~mm}$ in thickness.

The resorbable plugs can be made out of collagen or synthetic biodegradable polymers and are used to achieve a temporary occlusion of the lacrimal puncta in order to ensure that a future permanent occlusion can be indicated.

\section{Lacrimal puncta plugs}

Except keratoconjunctivitis sicca, there are other pathologies such as epiphora due to a partial or total stenosis of the lacrimal puncta which can be addressed by plugs. For this, different available plugs can improve the drainage of the tears by recreating the natural lacrimal path, allowing tears to drain through. The plugs are left in place for a few weeks allowing remodeling the lacrimal puncta (OZGUR et al [8]; CHANG et al [9]). If the patient has stenosis of the lacrimal puncta and canaliculi, a mini Monoka stent can be used for the catheterization of the lacrimal puncta and canaliculi in the same time and are convenient in case of an occlusive pathology of both (GUPTA et al [10]).

\section{Lacrimal canaliculi and the total lacrimal drainage system intubation}

The intubation stents regardless the materials that are made of have some common elements. They are introduced through superior and/or inferior lacrimal punctum and have a guidance system which allows passage along the nasolacrimal duct. After they are set into the right position, their length can be adjusted according to the lacrimal pathway extent and surgeon's wish. The tubes are made of soft and biocompatible materials which allow them to rest in position for a long period. Depending on the material, there are plain silicone tubes and silicone tubes with a surface treatment PVP (polyvinylpyrrolidone) in order to improve the hydrophilic properties of silicone. And, as depending on the thread-guide, the intubation can have a metallic thread-guide or a polypropylene thread-guide. Some intubation stents, such as MiniMonoka, don't have a thread-guide. As regarding the length of the lacrimal system treated with intubation stents, there are available long stents that ensure a total catheterization of the lacrimal system and short stents for one or both lacrimal canaliculi.

\subsection{Monocanalicular intubation}

The Monoka stent has it's name derived from Monoone and Ka- canalicular. It is a long monocanalicular, silicone tube with a metallic thread-guide, stabled to the lacrimal puncta which allows catheterization of the entire nasolacrimal duct. The metallic part acts as guidance allowing the passage of the stent throughout lacrimal system exiting at the level of the inferior nasal meatus where we can cut it, thus avoiding the exposure of the stent outside the nose. It is available in different sizes, for children (LEE et al [11]) and adults. It has three parts, one stabled to the lacrimal punctum (PFD "Punctal Fixation Device"), a silicone tube and a metallic thread-guide (FAYET et al [6]).

Mini Monoka stent has an identical punctal fixation device as Monoka but, the silicone tube has a length of $35 \mathrm{~mm}$ without a thread-guide. It is believed that a tube longer than $12 \mathrm{~mm}$ it is able to canalize both the superior or inferior canaliculus and the common canaliculus (GUPTA et al [10]) (Fig.4). The main advantage is that can be catheterized the lacrimal canaliculus without the need to pull out the tube from the nose. Due to the lack of the thread-guide, the tube can easily get stuck into the lacrimal canaliculus, thus making it impossible to reach the lacrimal sac.
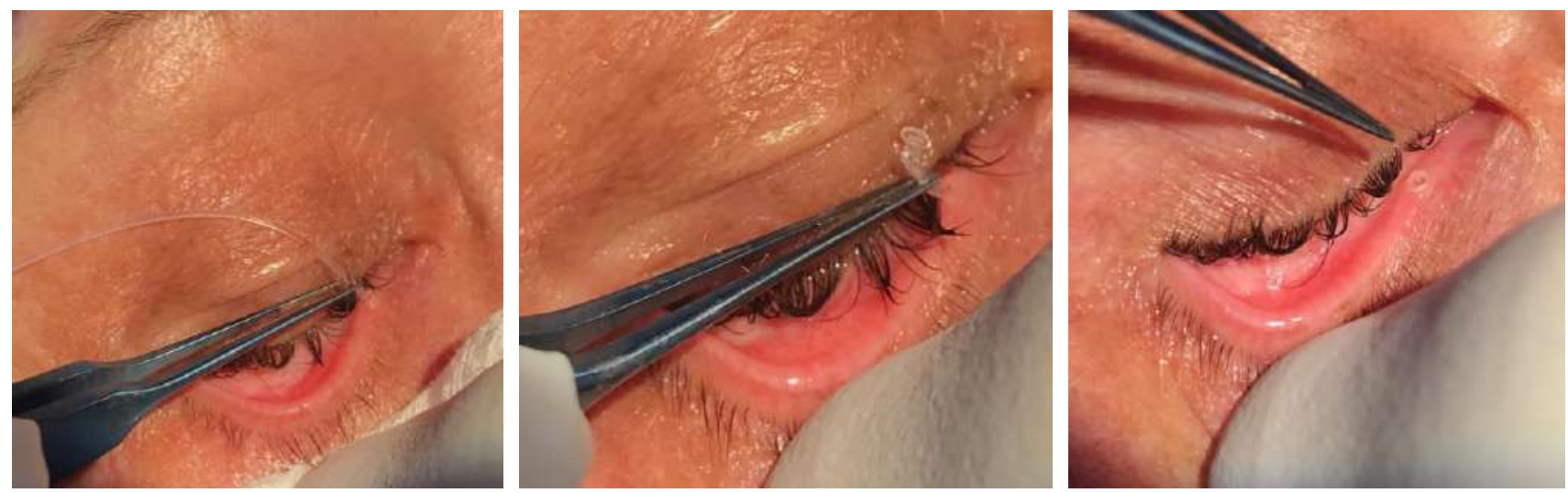

Figure 4. The insertion of mini Monoka through the inferior lacrimal punctum. 
Monoka-Crawford stent is a Monoka stent with a different metallic thread-guide. It consists of a Crawford type tip, olive tip, which in contact with the lacrimal system structures or nasal mucosa is harmless (NEMET [1]; ORGE \& BOENTE [2]; TONG et al [13]).

Masterka stent ("pushed" Monoka) also has an identical punctal fixation device as Monoka (FAYET et al [6]; RAJABI et al [12]; LIN et al [14]; FAYET et al [15]) but the thread-guide is a thin metallic stylet coated by a silicone tube with a diameter greater than $0.96 \mathrm{~mm}$. In order to choose the right stent length, a marked probe similar to a Bowman first should be introduced (Fig. 5).

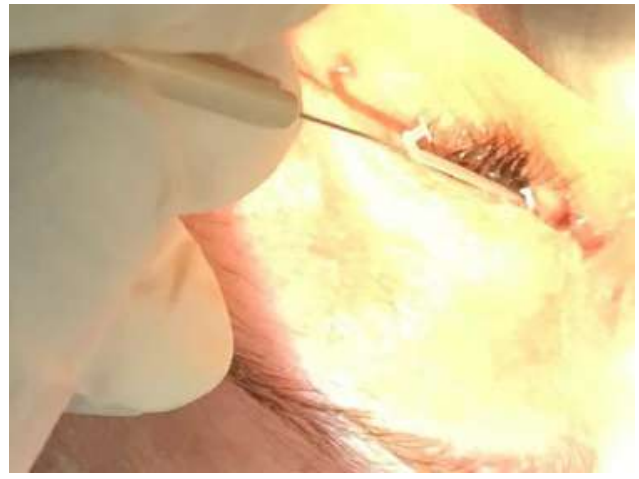

Monoka-Ritleng stent is a Monoka stent where the metallic probe is replaced by a long polypropylene threadguide with special physical properties such as flexibility, strength and minimal thickness, being able to enter the Ritleng probe (Fig. 6a). For performing this procedure first, the Ritleng probe has to be introduced into the nasolacrimal duct and then the polypropylene thread-guide (Fig. 6b) is inserted until the nasal fossa, where is partial retrieved with a Ritleng hook or a endonasal forceps under endoscopic visualization (LIN et al [14]) (Fig. 6c).

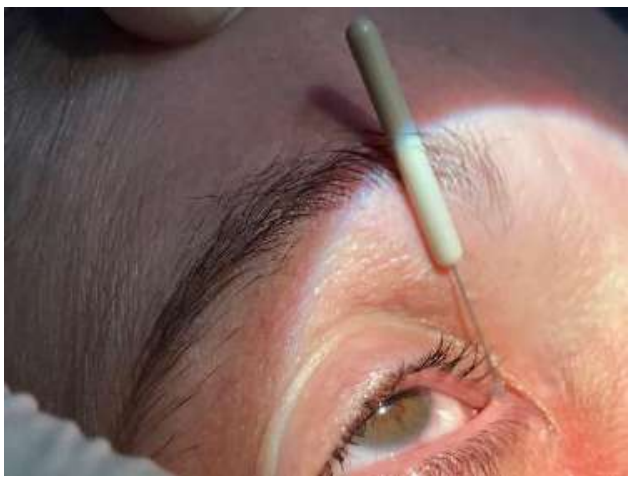

Figure 5. The insertion of Masterka stent.

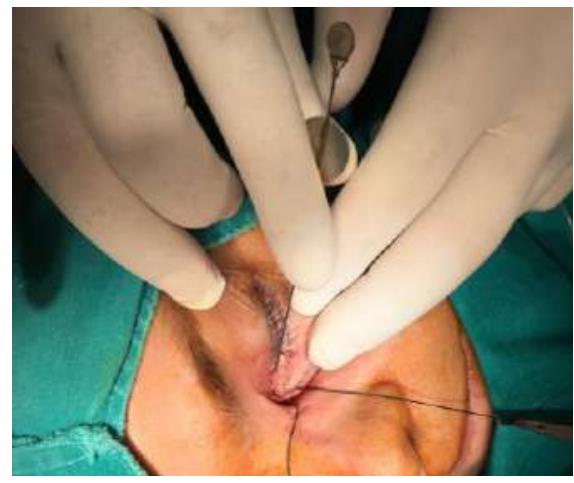

a)

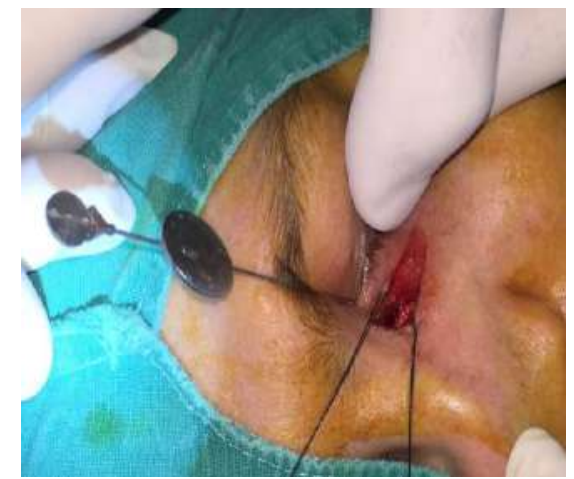

b)

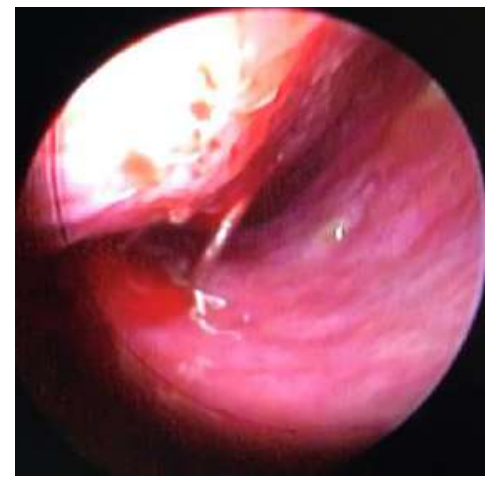

c)

Figure 6. The Monoka-Ritleng stent insertion.

Once the polypropylene thread-guide has been exposed outside the nasal fossa, we can pull back, outside the lacrimal ducts, through the lacrimal puncta, the Ritleng probe and thus separating it from the polypropylene threadguide (light blue portion of the thread). After continue with the extraction of the polypropylene thread-guide outside the nose until the silicon tube is pulled along with it into the lacrimal ducts, similar to Monoka.

\subsection{Bicanalicular stents}

Bicanalicular intubation devices have elements in common that allow the catheterization of both lacrimal canaliculi. For e.g. they are made of a silicone tube or PVP (polyvinylpyrrolidone) connected at each end to a threadguide, which can be metallic as in bicanalicular stents BIKA ${ }^{\circledR}$ and Crawford or from polypropylene as in Ritleng ${ }^{\circledR}$ stents. Bicanalicular stent BIKA® (BI from two and KA from canaliculi) consists of a silicone 0.6-1.18 mm diameter connected at the extremities with a metallic thread-guide available in different sizes, with a length of $50 \mathrm{~mm}$ and a thickness of $0.8 \mathrm{~mm}$ for catheterization after DCRS (dacryocystorhinostomy) and a length of $40 \mathrm{~mm}$ with a thickness of $1.2 \mathrm{~mm}$ in case of DCRS failure. For infants, a length of 55-60 mm and a diameter of 0.4-0.8 $\mathrm{mm}$ are appropriate (RAJABI et al [12]; LIN et al [14]).

The bicanalicular Crawford $®$ stent is a variant of BIKA ${ }^{\circledR}$ and has a metallic thread-guide with a thickess of $0.7 \mathrm{~mm}$ such as BIKA ${ }^{\circledR}$ but the tip has a metallic olive with a diameter of $1 \mathrm{~mm}$. Because of this olive, the passage through the nasolacrimal duct is easier and harmless and the retrieval is performed with a Crawford hook (TONG et al [13]).

The Ritleng ${ }^{\circledR}$ lacrimal intubation set is composed of a silicone tube with a thickness of $0.64 \mathrm{~mm}$ and at the 
extremities has a polypropylene thread-guide resembling that of Monoka-Ritleng ${ }^{\circledR}$ stent which is successively introduced through superior and inferior lacrimal puncta with the help of a Ritleng probe, exiting the lacrimal pathways at the nasal fossa. Extraction of the thread-guides will engage the silicone tube through the lacrimal system. After that, the thread-guides are shortened and a knot between the two is made.

FCI Nunchaku ${ }^{\circledR}$ stent is used for catheterization of the lacrimal system without nasal retrieval. It is entirely made of silicone and the metallic guide is positioned inside the lumen pushing the tube through the lacrimal system. The two endings are inserted through superior and inferior lacrimal puncta

Bicanalicular autostable intubation stent is a type of Nunchaku stent with a length of $25-45 \mathrm{~mm}$ which can catheterize just the superior, inferior canaliculi and common canaliculus. The extremities of the stent have silicone wings that interfere with a possible spontaneous dislocation from the canaliculus. Inside the silicone lumen there is a metallic guide.

The main indications of these stents are lacrimal canaliculi and/or the common canaliculus occlusion. Other recommendations are the nasolacrimal duct obstruction as a first approach or in case of failure of simple probing with a Bowman probe in the congenital obstruction (chronic dacryocystitis), stenting in case of an eyelid surgery especially if the inner canthus is involved, nasolacrimal duct obstructions in adults and after DCRS in order to maintain open the surgically performed aperture $a b$ interno or ab externo, in surgery for palpebral laceration involving the lacrimal canaliculus. There have been reported promising results for adult lacrimo-nasal occlusion after the silicon stents (PSILAS et al [16]).

Many advantages come along with the stents, such as the possibility to catheterize the lacrimal system under local or locoregional anesthesia and occasionally in reactive patients, under a mild sedation, the ability to preserve the entirely lacrimal system, the absence of surgical incisions or sutures, therefore without scarring and the possibility to repeat the procedure. Stent insertion is an office procedure and the patients feel more comfortable due to the short recovery time after the procedure (PSILAS et al [16]; YU et al [17]) also, the materials from which the stents are made and the lack of sutures make them easier to bear.

The disadvantages are related, especially in adults, to the incapacity to obtain a enough dilatation of the nasolacrimal duct (SILBERT [18]; ANDERSON \& EDWARDS [19]). Also, a rise in intranasal pressure during nose blowing or loud snoring can be involved in stent mobilization. Sometimes the patient, through a tenacious massage of the area over the lacrimal sac can cause a partial or total displacement of the stent into the lacrimal system, such as the collaret enters the lacrimal canaliculi, or suffers a medial traction with the appearance of a lacrimal pseudopunctum. There have been revealed also complications such as corneal abrasion, corneal ulcer, cellulites or pyogenic granuloma (REPKA et al [20]). Occasionally, in bicanalicular stents such as BIKA®, in time, due to a permanent apposition between the medial parts of the lids, a medial symblepharon can form.

2.3. Nasolacrimal duct catheterization with a polyurethane stent

Catheterization with a polyurethane stent is an effective method, with advantages (short procedure time, locoregional anesthesia and the possibility to evaluate the lacrimal patency at the end) and disadvantages the inabilities to perform catheterization in the severe lacrimal stenosis, sometimes pain, rarely intense during the procedure and uncommon prompt or late fibrosis of the nasolacrimal duct or the lacrimal sac (YAZICI et al [21]; YAZICI et al [22]), which can be taken into account in order to avoid dacryocystorhinostomy. Due to a relatively small number of treated patients there are no clear conclusions regarding the success rate of this procedure. As in case of any procedure, short-term complications (the anesthesia quality, the pain which is rarely profound, bleeding, iatrogenic false passages, entering the maxillary bone or the maxillary sinus, damaging the nasal mucosa, nasal cornet injury, local or general infections) and long-term complications (stent loss, stent blockage with a drainage failure (5-10\%) and ultimately episodes of dacryocystitis, severe inflammatory reactions in response to the stent) can occur.

\section{Stents for lacrimal drainage failure of the conventional stent}

All mono and bicanalicular stents preserve the natural path of the lacrimal drainage system. However, in some situations due to strong fibrosis, scars, traumatism, dilacerations, stenosis, it is required a new path to maintain the flow of tears through the nose. Some of the stents presented before like BiKA stent or Monoka stent can maintain the stoma open and can increase the procedure 's chances of success.

\subsection{Lester-Jones tube}

The tube is the final solution in the case of a total and definitive occlusion of lacrimal ducts and lacrimal puncta. Conjunctiv dacryocystorhinostomy(CDCR) with the insertion of a Lester-Jones tube is a solution in the case of failure of other used procedures in the case of canalicular obstruction treatment . CDCR is a procedure by which a fistula is created between the inner angle of the palpebral fissure and the lacrimal sac resulting in a complete bypass of the lacrimal drainage system. In some situations, one end of the tube can be situated in the nasal cavity which allows the tears to move freely from the inner angle of the eye to the inside of the nose. Other indications of this procedure include lacrimal pump failure which may occur with Bell palsy and other causes of facial paralysis. Other materials such as silicone, acrylate were tried but the final results were weaker than in the case of glass.

\subsection{Endonasal splints Klap-Bernard}

A problem with the conjunctiv dacryocystorhinostomy is the closure of the stoma after the procedure. Among the frequently proposed solutions is the use of BiKa probes in the same time with the CDCR procedure or in the case of endoscopic CDCR and also the use of endonasal Klap- 
Bernard splints which are able to increase the endonasal CDCR success rate and can be easily extracted endonasally if the patient complains of a discomfort associated with it.

3.3. Endoscopic dacriocystorhinostomy and double margin stent technique

In some particular cases, especially when the ophthalmologist approach and stents cannot achieve convenient results, an endoscopic DCR is indicated for the lacrimal obstruction. This rhinologic approach creates a communication between the lacrimal sac and the nasal cavity in order to restore the physiologic lacrimal flow. The results are successful in up to $90 \%$ of uncomplicated cases (PENTTILA et al [23]), so it is considered that still a risk of lacrimal system obstruction. For this reason it has been created a double margin stent which was inserted transnasal at the bottom edge of the lacrimal sac and positioned in contact with the bony edges of the new created ostium (Fig. 7).

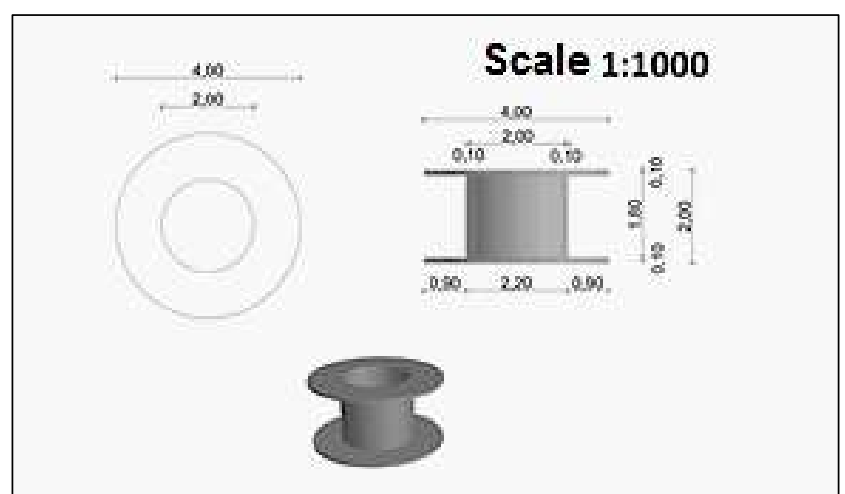

Figure 7. The double margin stent for DCR.

The surgical endoscopic technique consists of an endoscopic DCR, usually with general anesthesia and a Bowmann canulla inserted from the inferior lacrimal punctum, via the lacrimal sac in the nasal cavity, as guiding probe for the $4 \mathrm{~mm}$ double margin stent (Fig. 8 and Fig. 9 revealing the final position of the stent that ensure ensures a physiological drainage of the tears).
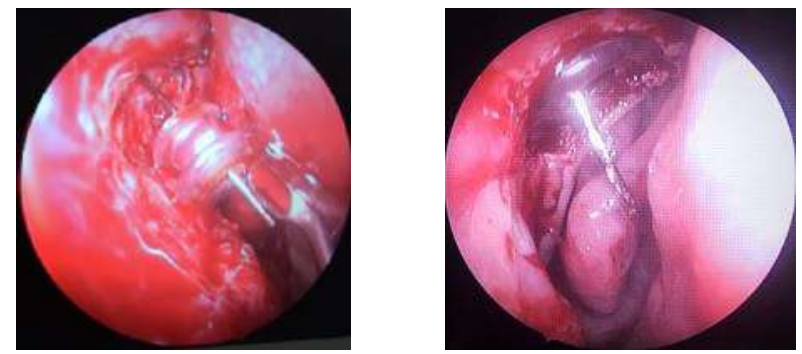

Figure 8. The Bowmann canulla guiding the lacrimal stent.
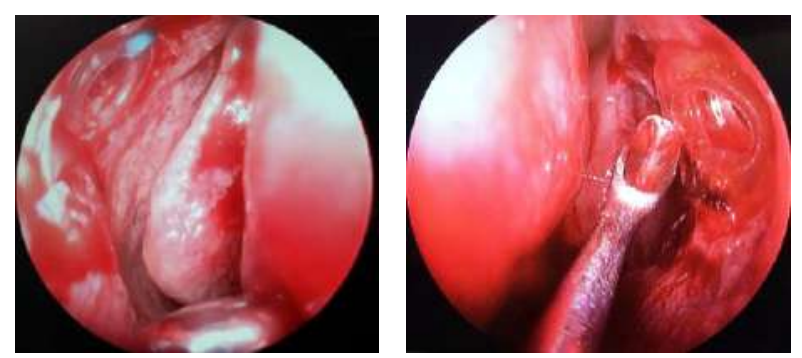

Figure 9. The final position of the stent.
There are different stenting and drainage systems used in the pathology of the lacrimal pathway that are associated with promising results following various procedures such as dilatation or bypassing of the lacrimal ducts. In some authors opinion their efficacy at least in the case of CDCR is limited because the final results are similar both in the case of using the stenting systems and in the absence of those. There are situations where their use is mandatory such as the prosthesis of the nasolacrimal duct with polyurethane stent, prosthesis of the lacrimal canaliculi in children after lacrimal probing or after surgical repair in case of lacerations. Another option is the use of perforated punctal plugs in complete or incomplete lacrimal puncta stenosis. This review compared the currently used stent with other described for endoscopic DCR and revealed that the currently used seems to get the best long-term results on lacrimal system obstructive pathology (ERKAN et al [24]). Endoscopic dacriocystorhinostomy and double margin stent technique has significantly decreased the risk of lacrimal pathway stenosis after endoscopic DCR, and represent a simple one-day surgical procedure easily accepted by the patients and a reliable surgical solution for lacrimal obstruction (BUDU et al [25]).

\section{References}

1. NEMET AY. The Etiology of Epiphora: A Multifactorial Issue. Semin. Ophthalmol, 31:275-279 (2016).

2. ORGE FH, BOENTE CS. The lacrimal system. Pediatr. Clin. North. Am., 61:529-539 (2014).

3. WURDEMANN HV. ANATOMY, PHYSIOLOGY AND PATHOLOGY OF THE LACRIMAL APPARATUS, MORE ESPECIALLY THE LACRIMAL SAC AND DUCT. Can. Med. Assoc. J., 21:667-669 (1929).

4. AHL NC, HILL JC. Horner's muscle and the lacrimal system. Arch. Ophthalmol.; 100:488-493 (1982).

5. KAKIZAKI H. [Medial canthal anatomy and the lacrimal drainage system]. Nippon Ganka Gakkai Zasshi 111:857863 (2007).

6. FAYET B, RACY E, KATOWITZ WR, KATOWITZ JA, RUBAN JM, BREMOND-GIGNAC D. Intralacrimal migration of Masterka((R)) stents. J Fr Ophtalmol (2018).

7. ERVIN AM, WOJCIECHOWSKI R, SCHEIN O. Punctal occlusion for dry eye syndrome. Cochrane Database Syst. Rev.; CD006775 (2010).

8. OZGUR OR, AKCAY L, TUTAS N, KARADAG O. Management of acquired punctal stenosis with perforated punctal plugs. Saudi J. Ophthalmol. 29:205-209 (2015).

9. CHANG M, AHN SE, BAEK S. The effect of perforated punctal plugs in the management of acquired punctal stenosis. J. Craniofac. Surg. 24:1628-1630 (2013).

10. GUPTA S, ALI MJ, ALI MH, NAIK MN. Assessing the outcomes of mini-Monoka stent dilatation for primary punctal stenosis using the lacrimal symptom questionnaire. Indian $J$. Ophthalmol. 66:269-271 (2018).

11. LEE H, AHN J, SHIN HH, PARK M, BAEK S. Effectiveness of primary monocanalicularnasal intubation with Monoka tubes and nasal endoscopic findings for congenital nasolacrimal duct obstruction with enlarged 
lacrimal sac and chronic dacryocystitis. J. Craniofac. Surg. 23:1638-1641 (2012).

12. RAJABI MT, ZAVARZADEH N, MAHMOUDI A et al. Bicanalicular versus monocanalicular intubation after failed probing in congenital nasolacrimal duct obstruction. Int. J. Ophthalmol. 9:1466-1470 (2016).

13. TONG NX, ZHAO YY, JIN XM. Use of the Crawford tube for symptomatic epiphora without nasolacrimal obstruction. Int. J. Ophthalmol. 9:282-285 (2016).

14. LIN AE, CHANG YC, LIN MY, TAM KW, SHEN YD. Comparison of treatment for congenital nasolacrimal duct obstruction: a systematic review and meta-analysis. Can. J. Ophthalmol. 51:34-40 (2016).

15. FAYET BE, KATOWITZ WR, RACY E, RUBAN JM, KATOWITZ JA. An update to monocanalicular stent surgery. Int. J. Ophthalmol. 9:797-798 (2016).

16. PSILAS $\mathrm{K}$, EFTAXIAS $\mathrm{V}$, KASTANIOUDAKIS J, KALOGEROPOULOS C. Silicone intubation as an alternative to dacryocystorhinostomy for nasolacrimal drainage obstruction in adults. Eur. J. Ophthalmol. 3:7176 (1993).

17. YU G, WU Q, LIN Q et al. Lacrimal intubation with the Ritleng system in congenital nasolacrimal duct obstruction in children. Zhonghua Yan Ke Za Zhi. 44:887891 (2008).

18. SILBERT DI. Success rate of placement of a bicanalicular stent for partial nasolacrimal obstruction in adults under local, monitored anesthesia care and general anesthesia. Saudi J. Ophthalmol. 31:140-144 (2017).

19. ANDERSON RL, EDWARDS JJ. Indications, complications and results with silicone stents. Ophthalmology 86:1474-1487 (1979).

20. REPKA MX, MELIA BM, BECK RW et al. Primary treatment of nasolacrimal duct obstruction with nasolacrimal duct intubation in children younger than 4 years of age. J AAPOS. 12:445-450 (2008).

21. YAZICI B, YAZICI Z, PARLAK M. Treatment of nasolacrimal duct obstruction in adults with polyurethane stent. Am. J. Ophthalmol 131:37-43 (2001).

22. YAZICI Z, YAZICI B, PARLAK M, TUNCEL E, ERTURK H. Treatment of nasolacrimal duct obstruction with polyurethane stent placement: long-term results. AJR. Am. J. Roentgenol. 179:491-494 (2002).

23. PENTTILA E, SMIRNOV G, TUOMILEHTO H, KAARNIRANTA K, SEPPA J. Endoscopic dacryocystorhinostomy as treatment for lower lacrimal pathway obstructions in adults: Review article. Allergy Rhinol (Providence). 6:12-19 (2015).

24. ERKAN AN, YILMAZER C, ALTAN-YAYCIOGLU R. Otologic T-tube in endonasal dacryocystorhinostomy: a new approach. Acta Otolaryngol.127:1316-1320 (2007) .

25. BUDU V, DECUSEARA T, MOCANU B, BAICAN R, TUSALIU M, COJOCARU D, BULESCU I. Stent technique for endoscopic DCR-our expertise. Romanian Journal of Rhinology, 6(21), 23-27 (2016). 